\title{
ASPECTOS LEGAIS DA ATUAÇÃO DO INMETRO - PARTICIPAÇÃO DOS PARTICULARES NO PROCESSO DE FORMAÇÃO DAS NORMAS TÉCNICAS
}

\section{ALBERTO NOGUEIRA JÚNIOR*}

I - À guisa de introdução; II - Sobre a participação dos particulares na formação das normas técnicas expedidas pelo INMETRO; Notas de referência

\section{I - À guisa de introdução}

É tradicional a atribuição de competência privativa à União Federal para legislar sobre "sistema de medidas".

Assim o art. 21, VI da CF/88; o art. $8^{\circ}$. , XVII, "j” da CF/69; e os arts. $5^{\circ} ., \mathrm{XV}$, "m" e $6^{\circ}$., ambos da $C F / 46$.

A competência privativa para legislar não impede que a União Federal regulamente, inclusive tecnicamente, todos os aspectos ligados ao sistema de medidas.

Estará, aí, no exercício de legítimo poder regulamentar.

Respeitados os limites impostos pela lei, inteira competência terão os órgãos e entidades da União Federal para integrar a legislação, notadamente no âmbito da regulação técnica, descendo às minúcias que sequer seriam finalidade a ser atingida pela lei - por definição, dotada de conteúdo genérico e abstrato e destinada a uma universalidade de pessoas. (1)

É sobre o tema da regulação técnica (2) e participação dos particulares na sua formação, que iremos tratar.

II - Sobre a participação dos particulares na formação das normas técnicas expedidas pelo INMETRO

A Lei no. 5.966, de 11/12/1973, instituiu o CONMETRO - CONSELHO NACIONAL DE METROLOGIA, NORMALIZAÇÃO E QUALIDADE INDUS-

* Juiz Federal da seção judiciária do Estado do Rio de Janeiro.

R. Dir. Adm.. Rio de Janeiro. 222: 23-37. out./dez. 2000 
TRIAL, "órgão normativo do Sistema Nacional de Metrologia, Normalização e Qualidade Industrial". (art. $2^{\circ}$., "caput").

Atribuiu ao CONMETRO, ainda, competências para "formular e supervisionar a política nacional de metrologia, normalização industrial e certificação da qualidade dos produtos industriais". (art. $3^{\circ}$., letra "a")

E, importante: "prevendo mecanismo de consulta que harmonizem os interesses públicos das empresas industriais e do consumidor". (art. $3^{\circ}$., letra " $a$ ", "fine").

A previsão da participação dos agentes econômicos privados na formulação das normas regulamentares de metrologia (3) e qualidade pode ser exemplificada, ainda, com o disposto no art. 16 do Decreto no. 75.074, de 10/12/1974. (4)

Mas esta participação dos agentes econômicos privados na formulação das normas públicas regulamentares destinadas a incidirem nas atividades comerciais e industriais daqueles não se encontrava formalmente processualizada.

Ao menos no sentido de situação jurídico - administrativa dinâmica, com reciprocidade de direitos e deveres, tanto por parte dos agentes econômicos privados, como por parte da Administração Pública, processo (5) este que se constitui em verdadeiro instrumento de legitimação do próprio Poder, (6) aproximando-o da sociedade.

Diferentemente do que se dava ao tempo do Estado Novo e dos regimes de exceção existentes quando vigentes as Constituições Federais de 1967 e de 1969, sob a égide do Estado Democrático de Direito, que pretendeu ser e passar a ser a Constituição Federal de 1988, toda atuação administrativa, por maior que seja sua discricionariedade quando do exercício de suas competências, tem que ser, por princípio, motivada, justificada, de modo a permitir ou o convencimento do administrado, ou o controle do ato pelo Poder Judiciário, inclusive sob o aspecto do devido processo legal, em seu aspecto estrutural.

A motivação é a explicitação das razões que levam o administrador a decidir de uma maneira ou de outra, diante de determinada situação, diante de determinados pressupostos, determinados fatos.

Como dito por LÚCIA VALLE FIGUEIREDO, “o administrador pode chegar à decisão "a", "b" ou "c", respaldando-se em parecer técnico, por exemplo; todavia, é importante e indispensável declinar as razões ensejadoras de tal decisão". (7)

Não se pode olvidar que é através da sua Administração que um Governo, o mais das vezes, será julgado (8) e que o descontrole político - administrativo, reforçado pelo caráter autoritário do exercício do poder regulamentar, tem sido, historicamente um dos fatores de violação dos direitos fundamentais das pessoas. (9)

$\mathrm{Na}$ verdade, a participação da sociedade na formação das decisões públicas, tem sido vista como uma técnica (10) de, através de uma maior "cooperação público privado", atingir-se uma "maior eficiência da administração pública". (11)

Trata-se de buscar a legitimação dos atos e decisões governamentais através de um devido procedimento administrativo e legal. (12)

A construção de uma utopia cuja necessidade, talvez mais do que em qualquer outra época, mais se faz premente hoje - o "Estado Inteligente", aquele onde " $a$ 
gestão administrativa, associada à sociedade civil", realiza a superação, através do princípio participativo, do " abismo existente entre o sistema normativo e a realidade social e do Estado de Direito e a sociedade civil". (13)

A tomada de decisões por parte dos órgãos administrativos, para poder ser juridicamente válida, terá que ser obtida democraticamente, não só através da oitiva dos interessados diretos e de outros possíveis, no ato a ser expedido, mas também quando da efetiva expedição do ato, sempre através de uma adequada fundamentação e motivação.

Tem-se, assim, um processo decisório que restou positivado em nosso ordenamento jurídico, em seus contornos básicos.

Vejam-se, a respeito, os arts. $5^{\circ}$, LIV e 37, "caput", ambos da CF/88; Lei no. 9.784 , de $29 / 01 / 1999$, arts. 29 , "caput" e $\$ 1^{\circ}$ e 37 , "caput"; $50, \S 1^{\circ}$ e inciso I; Decreto no. 2.455/98, arts. 21 e 22, que regulamentou a ANP, dentre outros. (14)

Processo decisório este em que não só os interessados diretos e a sociedade civil em geral têm o direito subjetivo de dele participar e de serem ouvidos sempre que as decisões administrativas puderem afetar uns e outros, mas também de terem acesso à informação necessária para manifestarem suas posições e de terem efetivamente sopesadas suas alegações (15)

Estes princípios e conclusões encontram-se refletidos, hoje, em outros ordenamentos jurídicos, como o italiano, sendo saudados como "bem vinda novidade a trazer uma nova relação entre o público e o privado". (16)

Daí porque, confirmando suas tendências evolutiva e ampliativa, integrou-se o direito dos interessados diretos e da sociedade em geral à participação na formação dos atos administrativos que possam vir a afetar suas situaçōes jurídicas ou interesses, e a terem uma adequada regulação de suas atividades, no rol dos direitos fundamentais passivel de afirmação via tutela judicial. (17)

Daí porque também resulta ser de direito estrito, estabelecido positivamente, a possibilidade de controle (18) judicial não só do procedimento decisório - regulamentar, mas, em última análise, da própria adequação e proporção (19) desta regulação.

Nada mais coerente à idéia de que "o juiz moderno atual é o aplicador dos Direitos Fundamentais inscritos nas modernas Constituições", dos "princípios que estão acima do Estado e que são confirmados pelos Tribunais". (20)

Tudo isto que foi dito é relevante, especialmente se for considerado que o INMETRO é entidade integrante do Sistema Nacional de Defesa do Consumidor, e sua atuação, especialmente no que pertine à "fiscalização de preços, abastecimento, quantidade e segurança de produtos" (21), inclusive podendo celebrar "termo de ajustamento de conduta às exigências legais" (22) e fornecer elementos probatórios da prática de crime contra as relações de consumo (23), sem falar na área de certificação de qualidade de bens e produtos destinados à exportação, importantíssima. (24)

Causa estranheza, assim, para dizer o menos, que não haja um único dispositivo no texto da Lei no. 9.933, de 20/12/1999, que fixe as normas gerais de participação 
dos particulares na formação das normas técnicas, notadamente as que tenham por objeto a segurança e a eficiência dos bens e produtos postos à disposição do consumidor.

Da comparação da Lei $\mathrm{n}^{9} 9.933$, de 20/12/1999 com a Lei $\mathrm{n}^{0} 5.966$, de $11 / 12 / 1973$, percebe-se que o maior objetivo daquela foi o de permitir, expressamente, a delegação de atividades pelo INMETRO (art. $4^{\circ}$.), a entidades públicas, tanto no campo da Metrologia Legal e da Certificação Compulsória de Qualidade (art. $4^{\circ}$, "caput"), como no de julgamento de recursos administrativos (art. $8^{\circ}$ ) e a entidades privadas (art. 12), no restante das áreas de atuação, como, e.g., a fiscalização nos estabelecimentos comerciais do cumprimento das normas administrativas emanadas por aquelas entidades públicas.

Manteve, a Lei n 9.933, de 20/12/1999, o espírito autoritário, do Estado policialesco, típico dos sistemas constitucionais e políticos vigentes anteriormente à Constituição Federal de 1988, no que pertine à participação dos agentes econômicos privados na formação das normas e das decisões administrativas.

Causa, todavia, surpresa - esta, porém, agradável - o texto da Resolução $\mathrm{n}^{\mathrm{n}}$ 04, de 16/12/1998, publicada no DOU de 31/12/1998, Seção 1, p. 65, do CONMETRO, que em várias passagens prevê a participação dos interessados diretos e da sociedade na formação das normas técnicas, como meio de se alcançar maior eficiência na sua observância. (25)

$O$ que vem a demonstrar que, por mais paradoxal que pareça, vem a autarquia e agência executiva (26) adotando postura mais aberta, democrática e participativa, do que a postura que seria de se esperar como decorrência da própria Lei $n^{\circledR}$ 9.933/99, editada pelo Congresso Nacional.

Exige a segurança jurídica, entretanto, que esta verdadeira contradição de comportamentos - o que seria de decorrer da Lei $\mathrm{n}^{2} 9.933 / 99$ e o que vem sendo adotado pela autarquia - venha a ser positivamente superada, assegurando-se, também por lei, procedimento específico para a participação eficaz dos agentes econômicos privados e da sociedade, em geral, na formação das normas técnicas referentes a todos os aspectos ligados à Metrologia e à Qualidade, até como forma de se evitar, no futuro, algum retrocesso, quando de mudança dos órgãos de direção da autarquia e agência executiva.

Advirta-se, por último, que a reformulação do modo de atuação normativa dos órgãos da Administração Pública, em geral, e do INMETRO, em particular, pressupõe uma inevitável reorganização estrutural - recursos humanos, recursos financeiros, contínuo aperfeiçoamento da capacitação técnica de todos os seus departamentos, fixação de metas a alcançar, diretrizes principais a serem cumpridas, e assim por diante - associada a uma vontade política - tanto do Executivo como do Legislativo - sob pena de, em assim não se procedendo, condenar-se o órgão à frustração de não conseguir mais do que resultados pontuais, absolutamente insatisfatórios para as necessidades do País, no mundo globalizado e competitivo em que estamos começando a nos integrar - como, de resto, demonstra a experiência norte-americana. (27) 


\section{NOTAS DE REFERÊNCIA}

\section{(1) JOSÉ AFONSO DA SILVA, lembrando OSWALDO BANDEIRA DE}

MELLO, in "Curso de Direito Constitucional Positivo", ed. Revista dos Tribunais, $1985,3^{a}$. ed., pp. 565 e 571 , diz que: “O regulamento tem limites decorrentes do direito positivo. Deve respeitar os textos constitucionais, a lei regulamentada e a legislação em geral, e as fontes subsidiárias a que ela se reporta." Ademais, sujeita-se a comportas teóricas. Assim, não cria, nem modifica e sequer extingüe direitos $e$ obrigaçōes, senão nos termos da lei, isso porque o inovar originariamente na ordem jurídica consiste em matéria reservada à lei. Igualmente, não adia a execução da lei e, menos ainda, a suspende, salvo disposição expressa dela, ante o alcance irrecusável da lei para ele. Afinal, não pode ser emanado senão conforme a lei, em virtude da proeminência desta sobre ele."

(2) O termo "regulação" não é unívoco. JOÃO BOSCO LEOPOLDINO DA FONSECA, "Direito Econômico", Forense, Rio de Janeiro, 1999, 2a . ed., p. 240, diz que: "Regulação econômica - a atividade neste campo pode dar-se sob o enfoque das normas destinadas a, de alguma forma, influir na concretização do fenômeno econômico e, para consegui-lo, o Governo condiciona, corrige, altera os parâmetros naturais e espontâneos do mercado, mas neste caso o faz sob dois enfoques: o de uma simples fiscalização administrativa da atuação dos agentes econômicos e o de uma influência mais determinante, quer sob o aspecto de estímulo quer sob o de apoio da atividade econômico". O significado, aqui, é o de exercício de poder de polícia. Como dito por DIOGO DE FIGUEIREDO MOREIRA NETO, "Curso de Direito Administrativo, Forense, Rio de Janeiro, 1992, 10". ed., p. 294: "Poder de polícia é a atividade administrativa que tem por objeto limitar e condicionar o exercício de direitos fundamentais, compatibilizando-os com interesses públicos legalmente definidos, com o fim de permitir uma convivência ordeira e valiosa"; ODETE MEDAUAR, “Direito Administrativo Moderno", Ed. Revista dos Tribunais, 1996, p. 365: "O âmbito de incidência do poder de polícia mostra-se bem amplo. Vai desde os aspectos clássicos da segurança de pessoas e bens, saúde e tranquiilidade públicas, até a preservação da qualidade do meio ambiente, natural $\mathrm{e}$ cultural, o combate ao abuso do poder econômico, a preservação do abastecimento de gêneros alimentícios"; CELSO ANTÔNIO BANDEIRA DE MELLO, "Elementos de Direito Administrativo", Malheiros Editores, 1992, 3ª ed., p. 252: "A atividade da Administração Pública, expressa em atos normativos ou concretos, de condicionar, com fundamento em sua supremacia geral e na forma da lei, a liberdade e a propriedade dos indivíduos, mediante ação, ora fiscalizadora, ora preventiva, ora repressiva, impondo coercitivamente aos particulares um dever de abstenção ("non facere") a fim de conformar-lhes os comportamentos aos interesses sociais consagrados no sistema normativo". Já para a OCDE, "regulation encompasses both structural regulation - concemed with the structure of an industry - and conduct regulation - concerned with the behaviour of those within an industry (although the distinction between the two is often blurred)", sendo de se acrescentar, ainda, a "regulation of standards". Na regulação estrutural, "the regulatory authority determines wich firms are allowed or required to engage in particular activities"; na 
regulação de conduta, "the common aproach was to require monopolies to carry out their activities without earning the "abnormal" profits that normally follow monopolistic production", fixando a entidade reguladora "the amount of profit companies are permitted to earn"; finalmente, na "regulação de standards", padrões de qualidade são estabelecidos "to constrain the behaviour of firms (e.g., health, safety or pollution standards)". ("Regulatory Reform, Privatisation and Competition Policy", Paris, 1992, p. 13); MARC ALLEN EISNER refere-se a "economic regulations", as quais "govern conditions under wich firms may enter and exit the market, competitive practices, the size of economic units, or the prices firms can charge" $\mathrm{e}$ "new social regulations", que são "designed to force corporations to accept greater responsability for the safety and health of workers and consumers, as well as for the safety and health production process" e que também objetivam "variouss social issues that are not directly economic (e.g., equal opportunity in employment)" ("Contemporary Regulatory Policy", Lynne Rienne Publishers, Inc., London and Colorado, 2000, p. 05); VITAL MOREIRA afirma que: “Desde logo, quanto à amplitude do conceito, aparecem-nos três concepções de regulação (Jarass, 1987:77): a) em sentido amplo, é toda a forma de intervenção do Estado na economia, independentemente dos seus instrumentos e fins; b) num sentido menos abrangente, é a intervenção estadual na economia por outras formas que não a participação directa na actividade económica, equivalendo, portanto, ao condicionamento, coordenação e disciplina da actividade económica privada; c) num sentido restrito, é somente o condicionamento normativo da actividade económica privada (por via de lei ou outro instrumento normativo)". ("Auto - Regulação Profissional e Administração Pública", Almedina, Coimbra, 1997, pp. 34 e 35, apud MARCOS JURUENA VILLELA SOUTO, "Agências Reguladoras", in "RDA 216/128). MARCOS JURUENA VILLELA SOUTO, por sua vez, conclui que "na verdade, a regulação deve ser considerada sob três aspectos, a saber: a regulação de monopólios, em relação aos quais devem ser minimizadas as forças do mercado através de controles sobre os preços e a qualidade do serviço; regulação para a competição, para viabilizar a sua existência e continuidade; e regulação social, assegurando prestações de serviços públicos de caráter universal e proteção ambiental". Sem que se queira redigir outro trabalho em nota de referência, a respeito da "regulação de monopólios", vale a pena destacar a advertência contida no "XIV Informe de La Comisión Europea sobre La Política de Competéncia (1984)", apud ROBERTO DROMI, "Derecho Comunitário", Ed. Ciudad Argentina, 1996, p. 337: "La política de competencia tiene como objeto permitir al proceso competitivo desarrolar sus efectos benéficos y contribuir así a la realización de un mercado común. Esto no significa que el mercado tenga que constituir en todos los casos el modo exclusivo de regulación de la actividad económica: la evolución espontánea de las fuerzas del mercado podería en ciertos casos reducir o incluso suprimir la competência. La política de competência debe buscar un equilibrio para que el libre juego del mercado, ajustado cuando sea necesario por intervenciones selectivas, asegure el mantenimiento de una competência no falseada”. (grifei) Também oportuna a observação de EDUARDO C. SCHAPOSNIK: “A grande empresa necessita, para seguir crescendo internacionalmente, da liberdade de mercado entre os países. Ou seja, que desapareçam 
as interferências oficiais para criar suas próprias interferências. Desta maneira, a regulamentação do mercado será um fato para o entendimento entre os oligopólios setorialmente dominantes." ("As Teorias da Integração e o MERCOSUL”, Editora da UFSC, 1997, p. 103). Daí a importância da participação democrática, aberta (no sentido emprestado por KARL POPPE), pluralítisca e qualificada na produção dos atos regulamentares normativos técnicos, que mais se acentua se se observar que um dos óbices ao pleno desenvolvimento do MERCOSUL é, justamente, a ausência de harmonização dos critérios de regulação técnica acerca dos bens e produtos fabricados nos respectivos países integrantes.

(3) Segundo o item 06 da Resolução no 11, de 12/10/1988, do CONMETRO, "entende-se como metrologia legal a parte da metrologia que se refere às exigências legais, técnicas e administrativas, relativas às unidades de medida, aos métodos de medição, aos instrumentos de medir e às medidas materializadas".

(4) "Art. 16 - O Diretor - Geral do Instituto Nacional de Pesos e Medidas, considerando as características peculiares dos vários setores componentes do parque têxtil nacional, poderá, mediante requerimento fundamentado dos interessados ou dos órgãos de classe representativos da respectiva categoria econômica, estabelecer regimes especiais de indicação da composição percentual de matérias-primas, para os casos não previstos neste Regulamento." (grifei) Como visto, antecipou o conteúdo do art. $4^{\circ}$, inciso III da Lei $\mathrm{n}^{\mathrm{O}} 8.078 / 90$ Código de Defesa do Consumidor.

(5) Não é incorreto falarmos em "processo", visto que, como dito por ADA PELLEGRINI GRINOVER, ARAÚJO CINTRA e CÂNDIDO RANGEL DINAMARCO, "processo é conceito que transcende ao direito processual. Sendo instrumento para o legítimo exercício do poder, ele está presente em todas as atividades estatais (processo administrativo, legislativo)". ("Teoria Geral do Processo", Malheiros Editores, 1991, $8^{2}$ ed., p. 247)

(6) ODETE MEDAUAR, "Direito Administrativo Moderno", Ed. Revista dos Tribunais, São Paulo, 1996, p. 187, "fine”/188: "Assim, o processo administrativo caracteriza-se pela atuação dos interessados, em contraditório, seja ante a própria Administração, seja ante outro sujeito (administrado em geral, licitante, contribuinte, p. ex.), todos, neste caso, confrontando seus direitos ante a Administração". E mais adiante, à p. 189: “A processualidade está associada ao exercicio do poder. O poder é, por si próprio, autoritário. No âmbito estatal, a imperatividade característica do poder, para não ser unilateral e opressiva, deve encontrar expressão em termos de paridade e imparcialidade do processo pré-ordenado. Daí a importância dos momentos de formação da decisão como legitimação do poder em concreto, pois os dados do problema que emergem no processo permitem saber se a solução é correta ou aceitável e se o poder foi exercido de acordo com as finalidades para as quais foi atribuído." (grifei)

(7) in "Estado de Direito e Devido Processo Legal", RDA 209/14-15. Daí porque, como salientado por ARTURO HOYOS, a Suprema Corte Norte-Americana decidiu, já nos idos de 1962, que "los funcionarios públicos deben de proveer a la persona com una explicación, usualmente por escrito, justificando la acción que 
afecta adversamente a individuos o a grupos indicando en su decisión al funcionário público respectivo las razones y las pruebas sobre las cuales dicha decisión descansa, de tal forma que pueda impugnares posteriormente". ("El Debido Proceso", Ed. Témis S/A, Colômbia, 1998, p. 26)

(8) Como dito por LUIGI MANZETTI, "regulation often touches very sensitive interests and does, therefore, become emmeshed with politics. (...) As a result, since the 1980s, students of regulation have increasingly focused on the importance of politics and ideology in shapping regulation". ("Latin America Regulation Policies in the Post - Privatization Era", in "Regulatory Policy in Latin America - Post - Privatization Realities", North - South Center Press, University of Miami, 2000, p. 02). Em sentido análogo, GEORGE LANDAU, apud EDUARDO SCHAPOSNIK, (op. cit., p. 123, "fine"/124): "Segundo ele (refere-se a LANDAU), de nada vale começar a considerar os problemas menores que determinam a ineficácia parcial ou relativa da administração, ou seja, o estudo dos microproblemas, mas que deve ser julgada no plano dos grandes problemas, que vão desde o planejamento até a tomada de decisões e a execução das ordens que emanam dos órgãos públicos do Estado. $O$ resultado de uma administração será decisivo para julgar o resultado político de seu governo. Administração e política são indissociáveis, como o verso e o reverso de uma mesma medalha." (grifei)

(9) RAYMUNDO FAORO, "Os Donos do Poder", Porto Alegre, Ed. Globo, 1958, p. 210, apud ALBERTO VENÂNCIO FILHO, "A Intervenção do Estado no Domínio Econômico", Ed. Renovar, 1998, p. 28, diz que: “No Império, a regulação econômica do Estado fez sentir, com particular veemência, no comércio e indústria. Praticamente, tudo dependia do Governo, com autorizações, favores, tarifas protecionistas e concessões; fora da faixa do Tesouro não conseguia medrar a iniciativa privada". Refere-se ainda ALBERTO VENÂNCIO FILHO a DJACI MENEZES, "O Brasil no Pensamento Brasileiro", Rio de Janeiro, MEC/INEPC, s/d, p. 505, quando este diz que "no Manifesto Republicano de 1870 há esse brado de protesto..." a liberdade econômica suprimida por uma legislação restritiva, tais são praticamente as condições reais do atual sistema de governo". Ao tempo da Constituição Federal de 1969, toda a doutrina era unânime em reconhecer a existência de verdadeira planificação e dirigismo estatais, num regime que se pretendia liberal. Assim, por exemplo, OSCAR DIAS CORREA afirma que "com efeito, enquanto o texto de 1969 era de tessitura neoliberal, a realidade, comandada pelo Estado, era intervencionista, estatizante, e levava a um predomínio incontrastável da sua atuação, em todos os campos, contrariamente ao espírito e à letra do texto. Isto porque, pelo art. 170 da EC no. 01/69, as atividades econômicas competiam, preferencialmente, às empresas privadas e só em caráter complementar o Estado organizaria e exploraria diretamente a atividade econômica. Este texto, em contraste com a realidade intervencionista "à outrance", quase planificadora (antes o fosse, porque seria mais sistemática) e assistemática". ("A Constituição de 1988 - Contribuição Crítica", Forense Universitária, 1991, ${ }^{a}$. ed., p. 200). Segundo CLÁUDIO PACHECO, o centralismo político, existente sob a égide da Constituição Federal de 1937, encontrava-se caracterizado por ter sido "rejeitado integralmente o princípio da separação de poderes, até mesmo ampliando o poder de regulamento do Executivo, ao pres- 
crever, no art. 11, que a "lei, quando de iniciativa do Parlamento, limitar-se-á a regular, de modo geral, dispondo apenas sobre a substância e os princípios, a matéria que constitui o seu objeto", acrescentando que "o Poder Executivo expedirá os regulamentos complementares"; e, no art. 13, ao estabelecer que "o Presidente da República, nos períodos de recesso do Parlamento ou de dissolução da Câmara dos Deputados poderá, se o exigirem as necessidades do Estado, expedir decretosleis sobre as matérias de competência legislativa da União, excetuadas as modificações à Constituição, legislação eleitoral, orçamento, impostos, instituições de monopólios, moeda, empréstimos públicos e alienação e oneração dos bens imóveis da União". ("Tratado das Constituições Brasileiras", v. V, p. 20, apud ROSALINA CORRÊA DE ARAÚJO, "Estado e Poder Judiciário no Brasil", Lumen Juris, Rio de Janeiro, 2000, p. 253, "fine"/254). Salienta ROSALINA CORRÊA DE ARAÚJO que "também pelo art. 73, o princípio da separação de poderes fora completamente inutilizado, pois o Presidente da República era a autoridade suprema do Estado, coordenador das atividades dos órgãos representativos superiores, e, ainda, responsável pela política interna e externa, além de se incumbir da promoção ou orientação da política legislativa de interesse nacional e de superintender a administração do País" e que "o Presidente da República, na vigência da Constituição de 1937, exercia seu poder extravagante não só sobre o Poder Legislativo, mas também sobre o próprio Poder Constituinte e assim se investia de autoridade para emendar e suspender a Constituição a seu arbítrio. A Constituição de 1937, para os constitucionalistas da época, esteve permanentemente suspensa, por todo o seu período de fictícia vigência, em tudo que pudesse limitar o exercício do poder ditatorial." (op. cit., p. 254/2550. Note-se que ao centralismo político fez-se acompanhar certa descentralização administrativa. Assim, segundo VICENTE FARIA COELHO, "a organização corporativa produz a descentralização econômica, isto é, o Estado deixa de intervir no campo econômico, como no regime de liberalismo político e econômico, sem que para isso tivesse expressão legal. Ao contrário, à própria produção caberá a tarefa de organizar-se por intermédio das corporações, que passam a ser órgãos do próprio Estado, exercendo funções delegadas de poderes públicos. O Estado surge, tão-somente, com seu caráter autoritário, para representar e defender o interesse nacional, decidindo os dissídios entre os vários setores da produção". E conclui: "preciso, porém, não ver nessa atitude por parte do Estado qualquer feição abstencionista, de vez que, embora deixando à própria instituição a tarefa de organizar-se, far-se-á por intermédio das corporações, que são órgãos do Estado, colocadas sob uma ação coordenadora, o qual poderá intervir sempre que se tome necessário defender o interesse nacional, não mais arbitrariamente, porém debaixo de perfeição expressão legal." (“A Organização Corporativa Brasileira", Cultura Política, 163-170, jun/41, p. 163, apud ALBERTO VENÂNCIO FILHO, op. cit., p. 48). Em sentido análogo, MANOEL GONÇALVES FERREIRA FILHO, "Direito Constitucional Econômico”, Saraiva, 1990, p. 19: “...Do contrário, continuará tudo como está: o art. 170, $\S 1^{\circ}$. da Constituição afirma que "apenas em caráter suplementar da iniciativa privada - Estado organizará e explorará diretamente a atividade econômica", mas, não havendo controle, ele expande continuamente a sua atuação, invadindo o terreno que pertence à iniciativa privada". Veja-se, ainda, PAULO BONAVIDES, "Constituinte 
e Constituição - A Democracia, o Federalismo e a Crise Contemporânea", EUFC, Fortaleza, 1985, p. 260.

(10) Sugestivo, a respeito, o título de, como sempre, interessante obra de DIOGO DE FIGUEIREDO MOREIRA NETO - "Direito da Participação Política - Legislativa - Administrativa - Judicial - Fundamentos e Técnicas Constitucionais da Democracia", Renovar, 1992.

(11) NURIA CUNILL GRAU, "Repensando o Público Através da Sociedade", Ed. Revan, trad. Carolina Andrade, 1997, pp. 234, 242 e 246: "Aumenta ainda a importância de novos modos de organização que facilitem a co-produção dos bens e serviços públicos o fato de que a cooperação público - privado é, cada vez mais, um dos requisitos para conseguir maior eficiência da administração pública. Neste sentido, é preciso considerar que os produtos da ação governamental - diferentemente da ação empresarial - não apenas são, em larga medida, intangíveis, como também, com frequiência, é indispensável a cooperação dos usuários dos serviços governamentais para produzi-los, além dos casos em que se pede que os usuários cumpram determinadas leis ou outros requisitos. (...) Será cada vez mais procurado este tipo de "co-produção", se o aumento da atividade legislativa fizer com que o setor público se considere mais como instituição geradora de normas que como instituição de serviços, dada a importância que o debate político atribui à proteção de bens públicos, do meio ambiente (...) ou da própria concorrência"; "A descentralização intra-organizacional (em agências autônomas) e político - administrativa (em níveis locais de governo), assim como a discricionariedade no interior das agências, sem enfoques contingentes num caso e sem fundamento democrático no outro, podem atentar contra os valores que as fundamentam, em particular, contra a democratização das relações de poder e a adaptação às necessidades do público"; "Em suma, a discricionariedade e a flexibilidade só podem ser assumidas como meios que viabilizam a capacidade de resposta das agências públicas, se tiverem fundamento democrático. Sem isto, podem reforçar a arbitrariedade e o autoritarismo e desnaturalizar o caráter público dos serviços".

(12) No sentido atribuído à expressão por LUHMANN, assim interpretado por PETER HÄBERLE: “Também a expressão legitimação pelo procedimento no sentido de LUHMANN é uma legitimação mediante participação no procedimento. Todavia, trata-se aqui de algo fundamentalmente diferente: participação no processo não significa aptidão para aceitação de decisões e preparação para se recuperar de eventuais decepções. (...) Legitimação, que não há de ser entendida apenas em sentido formal, resulta da participação, isto é, da influência qualitativa e de conteúdo dos participantes sobre a própria decisão." ("Hermenêutica Constitucional", trad. Gilmar Ferreira Mendes, Sergio Antonio Fabris Editor, Porto Alegre, 1997, p. 31, nota 48)

(13) FABIANA DE MENEZES SOARES: “O Princípio Participativo é conteúdo da expressão Estado Democrático de Direito, o único possível de diminuir, concretamente, o abismo existente entre o sistema normativo e a realidade social e do Estado de Direito e a sociedade civil. A gestão administrativa, associada à sociedade civil, realiza a afirmação de KLICSBERG (...), o Estado inteligente." 
("Direito Administrativo de Participação", Del Rey, Belo Horizonte, 1997, p. 157, "fine"/158.

(14) Lei $\mathrm{n}^{0} 9.784 / 99$, art. 29 - "As atividades de instrução destinadas a averiguar e comprovar os dados necessários à tomada de decisão realizam-se de ofício ou mediante impulso do órgão responsável pelo processo, sem prejuízo do direito dos interessados de propor atuações probatórias. $\S 1^{\circ}-\mathrm{O}$ órgão competente para a instrução fará constar dos autos os dados necessários à decisão do processo"; Art. 36 - " Cabe ao interessado a prova dos fatos que tenha alegado, sem prejuízo do dever atribuído ao órgão competente para a instrução e do disposto no art. 37 desta Lei"; Art. 50 - "Os atos administrativos deverão ser motivados, com indicação dos fatos $e$ dos fundamentos jurídicos, quando: I - neguem, limitem ou afetem direitos ou interesses. $\S 1^{\circ}-A$ motivação deve ser explícita, clara e congruente, podendo consistir em declaração de concordância com fundamentos de anteriores pareceres, informações, decisões ou propostas, que, neste caso, serão parte integrante do ato." (grifei) A Procuradoria Jurídica do INMETRO, na "Nota Informativa no. 40/2000", de 15/08/2000, in "Notas Informativas - INMETRO - $5^{\circ}$ Encontro dos Advogados da RNML", p. 52, reconheceu a compatibilidade entre a Lei $\mathrm{n}^{\circ}$ 9.784, de 28/01/1999 e a Portaria INMETRO no. 02, de 26.01.1999, que regulamentou o "Processamento e Julgamento das Infrações de Natureza Metrológica, de Normalização e de Certificação da Conformidade dos Produtos, de Processos e de Serviços".

(15) Como dito por ODETE MEDAUAR: “Em essência, o contraditório significa a faculdade de manifestar o próprio ponto de vista ou argumentos próprios, ante fatos, documentos ou pontos de vista oferecidos por outrem. É contradizer a posição oposta. Segundo CÂNDIDO DINAMARCO, o contraditório, fundamentalmente, quer dizer "informação necessária e reação possível" (Fundamentos do Processo Civil Moderno, 2a ed., 1987, p. 93); "Um dos desdobramentos da garantia do contraditório, assegurada pelo inciso LV do art. $5^{\circ}$ da Constituição Federal, situa-se na regra da informação em geral: significa o direito, atribuído tanto aos contribuintes como à própria Administração de obter conhecimento adequado dos fatos que estão na base da formação do processo e de que todos os demais fatos, dados, documentos e provas que vierem à luz no curso do processo"; "Um outro desdobramento da garantia do contraditório situa-se na vedação do uso de elementos que não constam do expediente formal, porque deles não tiveram ciência os sujeitos, tornando-se impossível eventual reação a tais elementos. Assim, inexistem dados ocultos nas atuações processualizadas"; "A atuação administrativa visível associa-se à prática do Estado democrático e, vista do ângulo da Administração, propicia clima de maior confiança nas atuações desta e, por conseguinte, leva a maior facilidade na adesão às medidas que edita". ("Processualização e Publicidade dos Atos do Processo Administrativo Fiscal", in "Processo Administrativo Fiscal", coord. Valdir de Oliveira Rocha, Dialética, São Paulo, 1995, $1^{\text {a }}$ ed., $1^{\text {a }}$ reimp., pp. 121-126)

(16) PALAZZO - SESÍN - ROLÓN LEMBEYE, "La Transformación del Estado", Depalma, Buenos Aires, 1992, p. pp. 74-75, a respeito dos arts. $7^{\circ}, 9^{\circ} \mathrm{e}$ 10 da Lei de Procedimentos Administrativos italiana de 1990 - (Legge 241 de 
07/08/1990) - “j) Se promueve la participación en el procedimiento no sólo de los interesados tutelados, sino también de todos aquellos que pudieran resultar afectados, conforme lo dispone el art. 7. "En el art. 9 se amplia considerablemente el concepto clásico de legitimación subjetiva al autorizarse la intervención en el procedimiento de cualquier sujeto portador de intereses públicos o privados, así como los titulares de intereses difusos constituídos en asociaciones o comités, a los cuales pueda producirles un perjuicio el acto a dictar. “k) Se garantiza con amplitud el derecho de los interesados y demás participantes en el procedimiento a tomar vista durante el desarrollo de él y presentar todos los escritos que estimen necesarios con la documentación correspondiente. "La administración deberá analizar los escritos que sean pertinentes en relación al objeto deI procedimiento previo a la emisión deI acto decisorio final, según lo dispuesto por el art. 10. “1) Queda expresamente normada la posibilidad de concluír el procedimiento mediante acuerdo con los interesados. En tal supuesto, se debe dejar constancia escrita bajo pena de nulidad, pudiéndose aplicar, cuando se haya previsto otra regla, los principios del Código Civil en materia de obligaciones y contratos en cuanto compatibles. "Nace, así, una novedosa posibilidad que da una tónica moderna a la relación entre lo público y lo privado en la reciente Ley de Procedimientos Administrativos italiana del año 1990".

(17) Face o disposto no art. 37, "caput" da CF/88 e no art. 22 do Código de Defesa do Consumidor, não há como se negar que, em nosso ordenamento jurídico, incluem-se entre os direitos fundamentais dos cidadãos a prestação de serviços públicos eficientes, contínuos e de qualidade, o que pode englobar, com certeza, a adequada regulação. Isto, creio, confirma a assertiva de FRANCISCO CÓRDOBA ZARTHA, in "La Carta de Derechos y la Jurisprudencia de la Corte Interamericana", Ed. Témis S/A, Santa Fé de Bogotá, Colômbia, 1995, p. 37, "fine" / 38, de que "la evolución y ampliación progresiva del complejo democrático puede contribuir al surgimiento de nuevos derechos fundamentales, como también pueden existir otros que hasta que no sean material de controversia pasarán inadvertidos y, por ende, no serán objeto de consideración para su expreso reconocimiento", assim como que "cada vez será necesárias otras nuevas aplicaciones de los elementos o criterios de base material (no formal) determinantes de la natureza fundamental de los derechos y libertades, que aún se traducirán em el reconocimiento expreso de otros derechos inalienables, asi como em la adopción de garantias para su salvaguarda". A participação da sociedade em geral também no processo de elaboração dos projetos de "atos normativos de especial significado político ou social", com divulgação de seus textos básicos na INTERNET "ou realizando audiência pública, com o objetivo de receber sugestōes por parte de órgãos, entidades ou pessoas a quem a medida se destina ou interessa" - contudo, sem caráter vinculativo para a Administração Pública no sentido da decisão a ser tomada - encontra-se prevista no art. 15 do Decreto no. 2.954, de 29/01/1999.

(18) No sentido empregado por OSWALDO ARANHA BANDEIRA DE MELLO para o termo "fiscalização", in "Aspecto Jurídico - Administrativo da Concessão do Serviço Público", RDA - Seleção Histórica 34/225, "verbis": "A fiscalização compreende os seguintes atos: a) de regulamentação da organização e 
funcionamento do serviço concedido; b) de autorização ou aprovação das atividades dos concessionários, cujo procedimento em casos predeterminados está sujeito a audiência prévia ou posterior dos inspetores fiscais; c) de supervisão sobre os serviços do concessionário e mesmo de interferência na gestão do próprio serviço, quando assim for julgado necessário ao bom desempenho dele; d) de verificação pura e simples de como vem sendo levado a efeito o serviço ou cumpridas as determinações de fiscalização"; veja-se, ainda, o disposto nos arts. 29, I a III e 32, ambos da Lei no. 8.987/75, "verbis": “Art. 29 - Incumbe ao poder concedente: I - Regulamentar o serviço concedido e fiscalizar permanentemente a sua prestação; II - Aplicar as penalidades regulamentares e contratuais; III - Intervir na prestação do serviço, nos casos e condições previstos em lei (...)"; "Art. 32 - O poder concedente poderá intervir na concessão, com o fim de assegurar a adequação na prestação do serviço, bem como o fiel cumprimento das normas contratuais, regulamentares e legais pertinentes. Parágrafo único - A intervenção far-se-á por decreto do poder concedente, que conterá a designação do interventor, o prazo da intervenção e os objetivos e limites da medida".

(19) A respeito, MIGUEL M. PADILLA, "Lecciones sobre derechos humanos y garantias", Abeledo - Perrot, Buenos Aires, 1986, p. 79, apud AGUSTÍN GORDILLO, "Después de la Reforma del Estado", Fundación de Derecho Administrativo", Buenos Aires, 1996, $1^{2}$ ed., p. 20, nota 4.36, assinalou que a Suprema Corte Norte - Americana, ao contrário da argentina, "estimó indispensable un examen de la realidad para poder decidir si los medios ordenados por el legislador mantenían una adecuada equivalencia respecto de los fines que buscaba alcanzar". Vale a pena recordar o disposto no art. $7^{\circ}$ do Decreto no. 2.954 , de 29/01/1999: "Os projetos de lei que disciplinem matérias técnicas ou tecnológicas complexas devem prever forma de aferição de resultados, tendo em vista a necessária adequação do direito positivo às novas situações, ao desenvolvimento tecnológico, ou ao desenvolvimento das relações fáticas e jurídicas. Parágrafo único - dos projetos de lei que reclamarem avaliação sistemática de resultados, deverá constar cláusula relativa à elaboração de "relatório de experiência" a serem encaminhados periodicamente a órgão dos Poderes Executivo ou Legislativo."

(20) ALBERTO NOGUEIRA, "Globalização, Regionalizações e Tributação", Renovar, 2000, p. 104; BERNARD SCHWARTZ, apud ALBERTO NOGUEIRA, op. cit., p. 105. Referindo-se ao caso "Dear v. Yellow Cab Co.", quando a Suprema Corte Norte-Americana "condenou a companhia a cobrar preços mais baixos, em certa medida e por determinado tempo, em benefício geral do público utente", LUÍS PAULO DA SILVA ARAÚJO FILHO, "Ações Coletivas : A Tutela Jurisdicional dos Direitos Individuais Homogêneos", Ed. Forense, Rio de Janeiro, 2000, p. 29, "fine" / 30. De forma mais tímida, a decisão proferida pela $4^{a}$ Turma do Eg. TRF-2a Região, A M S n 96.02.26059-9, dec. un. pub. DJU de 14/09/1999: "ADMINISTRATIVO. AUTO DE INFRAÇÃO. INMETRO. LEI n⿳0 5.966/73. I - A Lei $\mathrm{n}^{\mathrm{o}}$ $5.966 / 73$ conferiu ao INMETRO atribuições específicas para o controle normativo e fiscalizador dos pesos e medidas, bem como dos produtos oferecidos ao consumo. II - Atendidos os limites legais ao exercício da atividade fiscalizatória, não compete 
ao Poder Judiciário alterá-los, a pretexto de ter havido rigor por parte da Administração, a não ser quando demonstrado ter a autoridade administrativa agido com abuso, excesso ou desvio de poder. III - Recurso improvido." (grifei)

(21) Decreto no. 2.181 , de 20/03/1997, art. $3^{\circ}$, inciso VIII.

(22) Decreto no. 2.181 , de 20/03/1997, art. 6०, "caput"

(23) E.g., nas hipóteses do art. $7^{\circ}$, incisos II, III, IV e VII da Lei nº 8.137 , de $27 / 12 / 1990$.

(24) Como bem destacado, por sinal, por JOSÉ GERALDO BRITO FILOMENO, "Comentários ao Código de Defesa do Consumidor pelos Autores do Anteprojeto", Forense Universitária, 6" ed., 1999, p. 59: "A propósito, digno de nota é o programa nacional de qualidade e produtividade industrial lançado pelo governo federal, tendo como mestra e propulsora o INMETRO (...), ora integrando a estrutura também da mencionada Secretaria Nacional de Direito Econômico do Ministério da Justiça, o qual tem procurado otimizar os recursos materiais e humanos disponíveis no notável complexo de Xerém, Rio de Janeiro, tornando o órgão mais dinâmico. Além disso, tem-se procurado adaptar o País à chamada norma ISSO 9000 , já adotada por ele (sob a rubrica de norma NBR 19.000), ou seja, que estabelece padrões gerais e internacionais de qualidade industrial, sendo de vital importância para o mercado nacional, sobretudo o exportador para o Mercado Comum Europeu que, a partir de 1992, não mais aceita produtos que não estejam dentro dos referidos padrões."

(25) A Resolução aprovou as "Diretrizes para Emissão de Declaração do Fornecedor e para a Marcação de Produtos" (art. $2^{\circ}$ ). Em seu Anexo, define como "Declaração do Fornecedor" o "procedimento pelo qual um fornecedor dá garantia escrita de que um produto está em conformidade com os requisitos especificados" (item 2.2). O item 6.4 - dos "Requisitos para a regulamentação técnica que admita o uso da Declaração do Fornecedor" - estabelece que "deve ser garantido o envolvimento das partes interessadas, quando da elaboração dos documentos necessários ao estabelecimento da Declaração do Fornecedor". Merece destaque a lembrança, na "Introdução" às "Diretrizes para Emissão de Declaração do Fornecedor e para a Marcação de seus Produtos", que "a utilização indiscriminada da Declaração do Fornecedor e a não penalização pelo seu mau uso podem levar ao descrédito do sistema de avaliação da conformidade e da regulamentação, bem como à impunidade, à concorrência desleal e à propaganda enganosa".

(26) Decreto $s / n^{9}$ de $29 / 07 / 1998$, pub. DOU de $30 / 07 / 1998$, p. 22 , art. $1^{\circ}$.

(27) Assim, MARC ALLEN EISNER, JEFF WORSHAM, EVAN J. RINGQUIST, "Contemporary Regulatory Policy", Lynne Riienner Publishers, Colorado, 2000, p. 230: "Consumer protection regulation provides important lessons regarding the sources of regulatory policy change. First, as the case of the FTC would suggest, Congress and the president can successfully increase the level and vigor of regulation by providing funds for agency professionalization and broader legislative mandates. At the same time, a lack of such resources - as the case of the CPSC suggests can make effective regulation impossible. Congressional vulnerability to the mobi- 
lization of business interest can lead Congress to quickly retract its support, leading to a second important lesson: vigorous regulation may be decisive in undermining the policital support for regulation. (...) A third lesson: bureaucracy matters. The comparison of the FTC and the CPSC reveals that whereas the former pursued a sustained program of agency professionalization and institution building, the latter languished as a repository of bureaucrats who were not retained - often quite purposively - by the agencies with which they once worked. (...) The CPSC became little more than a clearinghouse for voluntary standard setting, characterized by a dearth of leadership and a sense of political irrelevancy." 


\section{O Estado na Preservação de Bens Culturais}

\section{O Tombamento}

Sonia Rabello de Castro

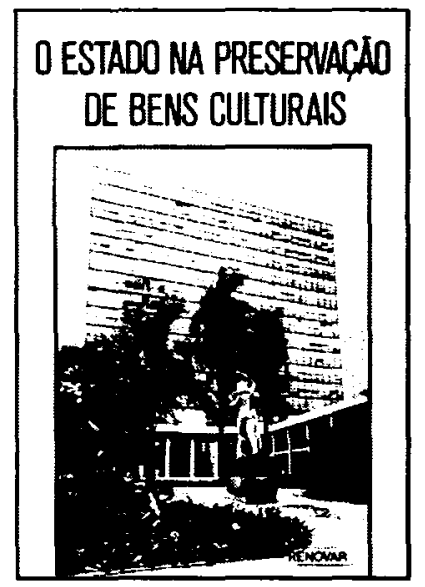

Esta obra trata do instituto jurídico do tombamento, explorando e reportando a experiência judicial brasileira na área, bem como analisando as formas e limites da atuação do Estado na preservaçāo do nosso Patrimônio Cultural. Enfim, é uma visão crítica do instituto do tombamento a partir da própria lei, e de sua leitura pela doutrina e jurisprudência nacionais.

Ref. 0035

Form. 14x21

Brochura

1991

158 págs.

\section{O Jeito na Cultura Jurídica Brasileira}

Keith S. Rosenn

Esta obra destaca as vertentes positivas e negativas do uso do "jeito" no Brasil nos tribunais, na administração e na vida econômica e política do país em geral. Em alguns dos seus aspectos, reflete uma fase já ultrapassada da nossa história, na qual o país ainda era dominado pelo paternalismo e corrompido pela infração, mas, em outros, apresenta problemas ainda atuais e que necessitam de solução urgente.

Ref. 0179

Form. 14x21
Brochura 1998
138 págs.

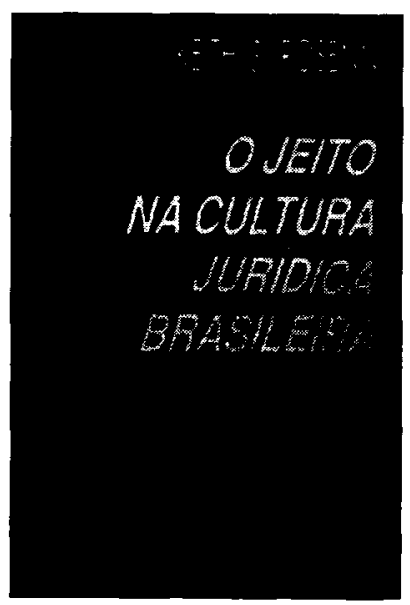

